\title{
Thermal effects in (oxy)nitride phosphors
}

\author{
Chun Che Lin ${ }^{1}$ and Ru-Shi Liu ${ }^{1,2^{*}}$
}

\footnotetext{
* Correspondence: rsliu@ntu.edu.tw ${ }^{1}$ Department of Chemistry, National Taiwan University, Taipei 106, Taiwan

2Department of Mechanical Engineering and Graduate Institute of Manufacturing Technology, National Taipei University of Technology, Taipei 106, Taiwan
}

\begin{abstract}
Technologies that control the chemical composition of white lighting-emitting diodes are promising means to enhance thermal properties and renew spectra generation. Although (oxy)nitride red phosphors have been available for more than a decade, the drawbacks of these devices still evidently remain with respect to the local environments of activators in a variety of nitridosilicates. Thermal effects, such as, thermal quenching, thermal ionization, and thermal degradation, are technologically important parameters that determine product reliability. In recent years, red phosphors, which can alter novel complexes with particular wavelengths, have been easily synthesized and used to minimize losses during energy conversion process. Silicon nitride ceramics contain a more highly condensed network compared with silicate because of the higher degree of cross-linking, edge-sharing $\mathrm{SiN}_{4}$ tetrahedron, and more covalent and stronger crystal field splitting. To provide a reasonable explanation for the relationship between photoluminescence and structure, an empirical model has been proposed, in which the changes in the chemical environment of the activators are attributed to strains resulting from atom displacements. In addition, the development of high-efficiency and cost-effective light-emitting diodes based on these luminescent materials has difficult challenges.
\end{abstract}

Keywords: Light-emitting diodes; (Oxy)nitride phosphor; Thermal quenching; Thermal ionization; Thermal degradation

\section{Background}

White light-emitting diodes (wLEDs) are a promising solid-state lighting technology that have a large number of revolutionary applications because they are energy-saving, robust, have long-lifetimes, and environment-friendly [1-3]. This technology, which is now extensively integrated into our daily lives, has replaced traditional incandescent or fluorescent light sources for less energy and viable options. Phosphor-converted white light devices consist of a blue or near-UV chip as excitation source, and have appropriate phosphor compositions that down-convert a portion of the chip emission to longer wavelengths. Therefore, phosphor has an important role in solid-state lighting (SSL), and should possess high chemical/thermal stability, high quantum efficiency (QE), suitable excitation and emission spectra, high reliability, and low cost [4,5]. Although numerous phosphors have already been investigated or developed for SSL applications, only a few of them can be practically applied to wLEDs. Aside from the drawbacks of low external quantum efficiency (EQE), high humidity, reabsorption, unsuitable spectral shape, and diverse morphology, thermal effects are seriously detrimental for phosphors, which hinder their commercialization.

(c) 2014 Lin and Liu; licensee Springer. This is an Open Access article distributed under the terms of the Creative Commons Attribution License (http://creativecommons.org/licenses/by/4.0), which permits unrestricted use, distribution, and reproduction in any medium, provided the original work is properly credited. 
Phosphor luminescence can be approximately described by four mechanisms. The perfect luminescence of dopants proceeds from the lowest position of the excited state to the ground state without thermal effects, as exhibited by the emission spectra (Figure 1a; green line). Unfortunately, numerous lanthanide activators display emission spectra with spectral intensity and positions that are easily affected by the environmental temperature. Heat is usually detrimental, and phosphor efficiency decreases through nonradiative relaxation as device temperature increases. This phenomenon indicates thermal quenching (TQ), and the phosphor will consequently shift to the emission peak wavelengths and decrease the luminescent intensity. The excited electrons can relax through radiative (Figure 1b; dotted green line) and nonradiative (Figure 1b; gray line) processes, such as photon emission and collisional quenching, respectively. According to the configurational coordinate model, the transition probability $(N)$ of a nonradiative relaxation process can be expressed as follows [6,7]:

$$
N=\operatorname{sexp} \frac{-\Delta U}{k T}
$$

where $s$ can be treated as a constant $\left(10^{13} \mathrm{~s}^{-1}\right)$ because it is weakly affected by temperature. Using Equation (1) and the luminescent probability $W$, luminescent efficiency $\eta$ can be expressed using the following formula $[6,7]$ :

$$
\eta=\frac{W}{W+N}=\left[1+\frac{s}{W} \exp \frac{-\Delta U}{k T}\right]^{-1}
$$

$\eta$ can also be calculated using the lifetime $[8,9]$ :

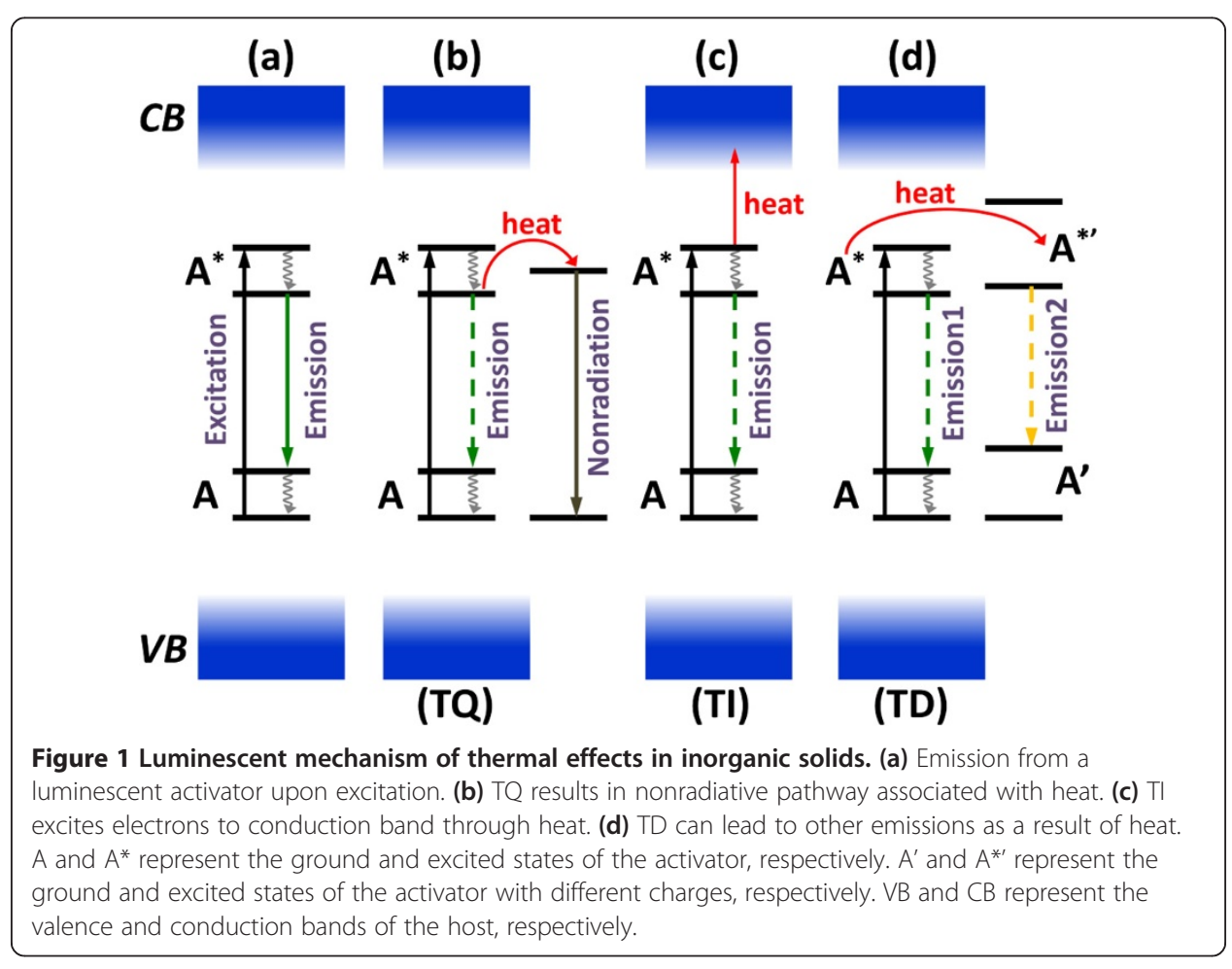




$$
\eta=\frac{\tau}{\tau R}
$$

where $\tau$ is the observed lifetime from the intensity decay curves and $\tau_{R}$ is the lifetime of the excited state without any nonradiative decay process. However, it is not possible to obtain the radiative lifetime $\left(\tau_{R}\right)$ through Judd-Ofelt theory only. It is conventional to measure an approximated value of radiative lifetime using an extremely dilute system. Figure 1 (c) shows the relative positions between the localized $5 d$ electron states of activators and the delocalized conduction band states of hosts. First, autoionization spontaneously occurs and no $5 d-4 f$ emission is observed when the lowest $5 d$ state is above the bottom of the conduction band. Such cases include $\mathrm{Ba}_{10}\left(\mathrm{PO}_{4}\right)_{4}\left(\mathrm{SiO}_{4}\right)_{2}: \mathrm{Eu}^{2+}$ [10], $\mathrm{Ln}_{2} \mathrm{O}_{3}: \mathrm{Ce}^{3+}$ [11], $\mathrm{LaAlO}_{3}: \mathrm{Ce}^{3+}[12]$, and the $\mathrm{Eu}^{2+}$ on the trivalent rare-earth sites in oxide compounds [13]. Second, the $5 d$ states of the activators are below the conduction band of the hosts in most $5 d-4 f$ emission situations. The $5 d$ electrons are ionized to the conduction band through thermal ionization (TI), which depends on the energy $\mathrm{E}_{\mathrm{dC}}$ between the $5 d$ state $(\mathrm{d})$ of the activator and the bottom of the conduction band (C) $[14,15]$. The activator $\mathrm{Eu}^{2+}$ located in the fluffy structure is easily oxidized to the trivalent species through high temperature. Therefore, the existence of $\mathrm{Eu}^{3+}$ can be observed in the photoluminescence $(\mathrm{PL})$ and X-ray absorption spectra. This phenomenon is called thermal degradation (TD) effect [Figure 1 (d)].

Thermal effects are detrimental for SSL technology. In the present study, a systematic review on the performance and mechanisms of (oxy)nitride phosphors for modern wLEDs applications was conducted.

\section{Methods}

Solid state reaction is a well-accepted classical reaction applied for micro-scale luminescent powders. For instance, nitridosilicate compounds $\left(\mathrm{M}_{2-\mathrm{x}} \mathrm{Si}_{5} \mathrm{~N}_{8}: \mathrm{Eu}_{\mathrm{x}}\{\mathrm{M}=\mathrm{Sr}, \mathrm{Ba}\}\right)$ [16] were successfully prepared through this method. A homogeneous mixture was prepared using stoichiometric amounts of powdered $\mathrm{Sr}_{3} \mathrm{~N}_{2}$ (Cerac, 99.5\%, 60 mesh), $\mathrm{Ba}_{3} \mathrm{~N}_{2}$ (Cerac, 99.7\%, 20 mesh), $\mathrm{Si}_{3} \mathrm{~N}_{4}$ (Aldrich, 99.9\%), and $\mathrm{EuN}$ (Cerac, 99.9\%, 60 mesh) in a glove box, and then packed in a molybdenum crucible. The mixture was reacted in a tube furnace at $1400^{\circ} \mathrm{C}$ for $16 \mathrm{~h}$ with flowing $90 \% \mathrm{~N}_{2}-10 \% \mathrm{H}_{2}$ atmosphere. Oxonitridosilicates composites $\left(\mathrm{Sr}_{1-\mathrm{x}} \mathrm{Si}_{2} \mathrm{O}_{2} \mathrm{~N}_{2}: \mathrm{Eu}_{\mathrm{x}}^{2+}\right)$ [17] were synthesized through the same method.

Second, a gas-pressure technique utilizing graphite heater was used for the synthesis of the oxonitridoaluminosilicates $\mathrm{M}_{1.95} \mathrm{Eu}_{0.05} \mathrm{Si}_{5-\mathrm{x}} \mathrm{Al}_{\mathrm{x}} \mathrm{N}_{8-\mathrm{x}} \mathrm{O}_{\mathrm{x}}(\mathrm{M}=\mathrm{Ca}, \mathrm{Sr}, \mathrm{Ba})$ [18]. Stoichiometric mixture of high purity $\mathrm{Ba}_{3} \mathrm{~N}_{2}, \mathrm{Sr}_{3} \mathrm{~N}_{2}, \mathrm{Ca}_{3} \mathrm{~N}_{2}, \alpha-\mathrm{Si}_{3} \mathrm{~N}_{4}, \mathrm{EuN}$, and $\mathrm{Al}_{2} \mathrm{O}_{3}$ was ground, placed in boron nitride crucibles, and fired in a gas-pressure sintering furnace (FVPHP-R-5, FRET-25, Fujidempa Kogyo Co. Ltd.) at $800^{\circ} \mathrm{C}$ under a vacuum of $10^{-2} \mathrm{~Pa}$. Reaction temperature was then increased and maintained at $1600^{\circ} \mathrm{C}$ for $2 \mathrm{~h}$ with flowing nitrogen gas (99.999\% purity). Moreover, this method afforded excellent results in the synthesis of nitridosilicates $\left(\mathrm{Ca}_{1-x} \mathrm{Li}_{x}\right)\left(\mathrm{Al}_{1-x} \mathrm{Si}_{1+x}\right) \mathrm{N}_{3}: \mathrm{Eu}[19]$.

Third, nitridosilicates $\left(\mathrm{MYSi}_{4} \mathrm{~N}_{7}: \mathrm{Eu}^{2+}\{\mathrm{M}=\mathrm{Ca}, \mathrm{Sr}, \mathrm{Ba}\}\right)$ [20] were synthesized from the stoichiometric mixture of $\mathrm{CaCO}_{3}, \mathrm{SrCO}_{3}, \mathrm{BaCO}_{3}, \mathrm{Y}_{2} \mathrm{O}_{3}$, and $\mathrm{Eu}_{2} \mathrm{O}_{3}$ through carbothermal reduction and nitridation. The starting materials and active carbon were thoroughly mixed and reacted at $1800^{\circ} \mathrm{C}$ for $2 \mathrm{~h}$ in a gas-pressure sintering furnace under a pressure of $0.92 \mathrm{MPa}$. 


\section{Results and discussion TQ effect}

The intensities of luminescent materials decrease with increasing temperature in a normal environment through the TQ effect. Excited electrons are promoted to a higher state of vibration excitation energy levels by absorbing external energy at high temperatures. Afterward, these excited electrons relax to the ground state of the activators through a non-radiative manner. The TQ effect affects the luminous efficiency of fluorescent compounds. For instance, nitride phosphors have an important role in wLED fabrication because of their high efficiencies and thermal stabilities. A size-mismatch between host and dopant cations affects the TQ conditions of the $\mathrm{M}_{1.95} \mathrm{Eu}_{0.05} \mathrm{Si}_{5-\mathrm{x}} \mathrm{Al}_{\mathrm{x}} \mathrm{N}_{8-\mathrm{x}} \mathrm{O}_{\mathrm{x}}$
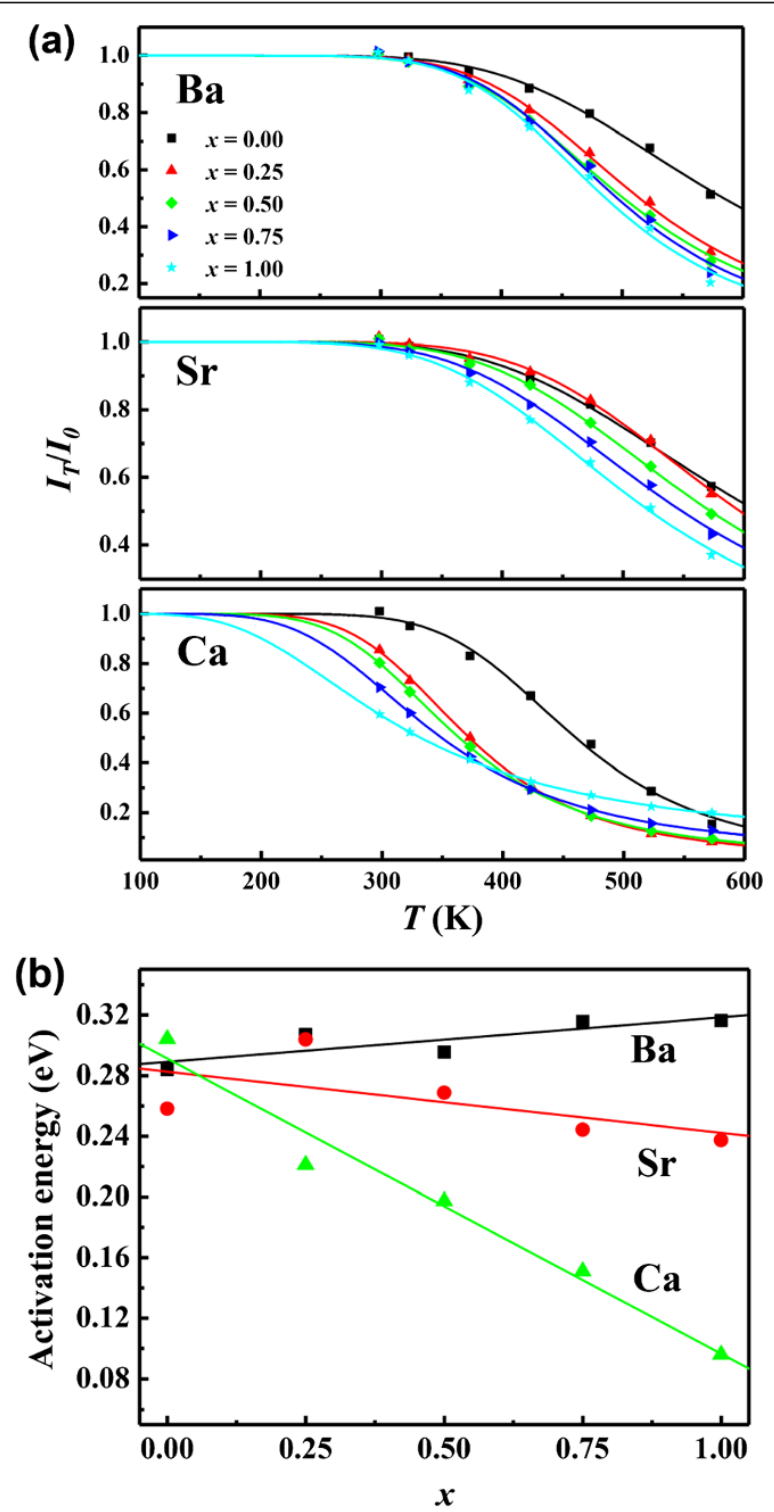

Figure 2 TQ properties of $\mathrm{M}_{1.95} \mathrm{Eu}_{0.05} \mathrm{Si}_{5-x} \mathrm{Al}_{x} \mathrm{~N}_{8-x} \mathrm{O}_{x}$ materials $(\mathrm{M}=\mathrm{Ca}, \mathrm{Sr}, \mathrm{Ba})$. (a) Temperaturedependent normalized-intensity curves are shown as functions of $I_{T} / I_{0}=\left[1+D \exp \left(-E_{a} / \mathrm{k} T\right)\right]^{-1}$ where $I_{0}$ (the intensity at $T=0$ ), $D$, and $E_{\mathrm{a}}$ (the activation energy) are refined variables. (b) The relations of the activation energies and components for different alkaline earth metal series. (Reprinted with permission from reference [18]. Copyright 2012, American Chemical Society). 

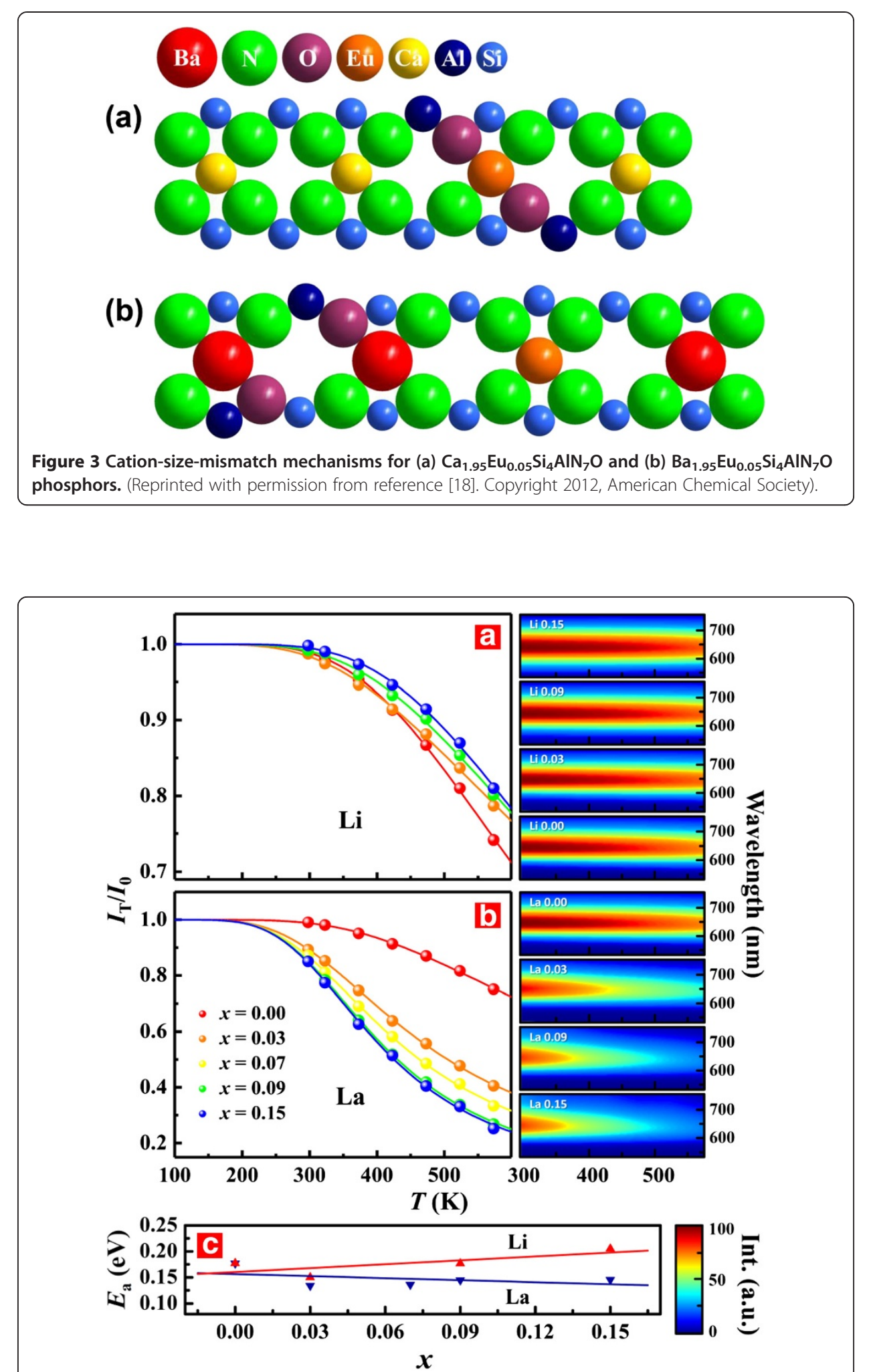

Figure 4 Thermal properties. Temperature-dependent normalized emission intensities for (a) $\left(C a_{1-x} L_{x}\right)$ $\left(A I_{1-x} S_{1+x}\right) N_{3}: E u$ and (b) $\left(C a_{1-x} L a_{x}\right)\left(A l_{1+x} S i_{1-x}\right) N_{3}$ :Eu samples $(x=0-0.15)$. These curves are fitted by $I_{T} / I_{0}=$ $\left[1+D \exp \left(-E_{a} / \mathrm{KT}\right)\right]^{-1}$. Photoluminescence spectra were obtained at $T=298 \mathrm{~K}$ to $573 \mathrm{~K}$, and is shown in the right hand side. (c) Activation energies as a function of variable $x$ for La and Li series. (Reprinted with permission from reference [19]. Copyright 2013, American Chemical Society). 
$(\mathrm{M}=\mathrm{Ca}, \mathrm{Sr}, \mathrm{Ba})$ materials, as shown in Figure 2. When $\mathrm{M}=\mathrm{Sr}$ and $\mathrm{Ba}$, the initial temperature for the TQ is maintained at around $300 \mathrm{~K}$. For $\mathrm{M}=\mathrm{Ca}$ series, temperature drastically but reversibly decreases to around $150 \mathrm{~K}$ when $\mathrm{AlO}^{+}$substitution increases to $\mathrm{x}=1$ (Figure 2a). The curves are fitted by the following equation [21]:

$$
\mathrm{I}_{\mathrm{T}} / \mathrm{I}_{0}=\left[1+D \exp \left(-\mathrm{E}_{\mathrm{a}} / k T\right)\right]^{-1}
$$

The activation energy $\left(E_{\mathrm{a}}\right)$ of different components can be obtained and described in Figure $2 \mathrm{~b}$. When $\mathrm{x}=0$, the quenching $E_{\mathrm{a}}$ values of the three series are around $0.28 \mathrm{eV}$, and largely deviate with increasing $\mathrm{x}$. These finding evidently indicates that the series follows the order of the thermal stability of $\mathrm{M}=\mathrm{Ba}>\mathrm{M}=\mathrm{Sr}>\mathrm{M}=\mathrm{Ca}$ in $\mathrm{M}_{1.95} \mathrm{Eu}_{0.05} \mathrm{Si}_{5-}$ ${ }_{x} \mathrm{Al}_{\mathrm{x}} \mathrm{N}_{8-\mathrm{x}} \mathrm{O}_{\mathrm{x}}$ materials. Figure 3 illustrates that variations in TQ were caused by the cation size-mismatch. This notable effect is ascribed to the surrounding-coordination of $\mathrm{Eu}^{2+}$ when the difference between large $\mathrm{Ba}^{2+}$ or small $\mathrm{Ca}^{2+}$, and the dopant $\mathrm{Eu}^{2+}$ is comparable with the difference between the anion radii $\left[{ }^{[4]} r\left(\mathrm{~N}^{3-}\right)-{ }^{[4]} r\left(\mathrm{O}^{2-}\right)=0.08 \AA\right]$. With the significant dispersion of size $\Delta_{\mathrm{r}}\left[{ }^{[8]} r\left(\mathrm{Eu}^{2+}\right)-{ }^{[8]} r\left(\mathrm{Ca}^{2+}\right)=1.25-1.12=0.13 \AA\right]$ in the $\mathrm{Ca}_{1.95} \mathrm{Eu}_{0.05} \mathrm{Si}_{5-\mathrm{x}} \mathrm{Al}_{\mathrm{x}} \mathrm{N}_{8-\mathrm{x}} \mathrm{O}_{\mathrm{x}}$ system, the lattice strain is relaxed by bonding numerous oxygen anions around the $\mathrm{Eu}^{2+}$ cations, as shown in Figure 3a. Hence, the thermal stability of the system decreases by increasng the $\mathrm{AlO}^{+}$substitution, which coincides with the activation energy (Figure $2 \mathrm{~b}$ ). $\mathrm{Eu}^{2+}$ is smaller than $\mathrm{Ba}^{2+}$ and prefers to be coordinated with
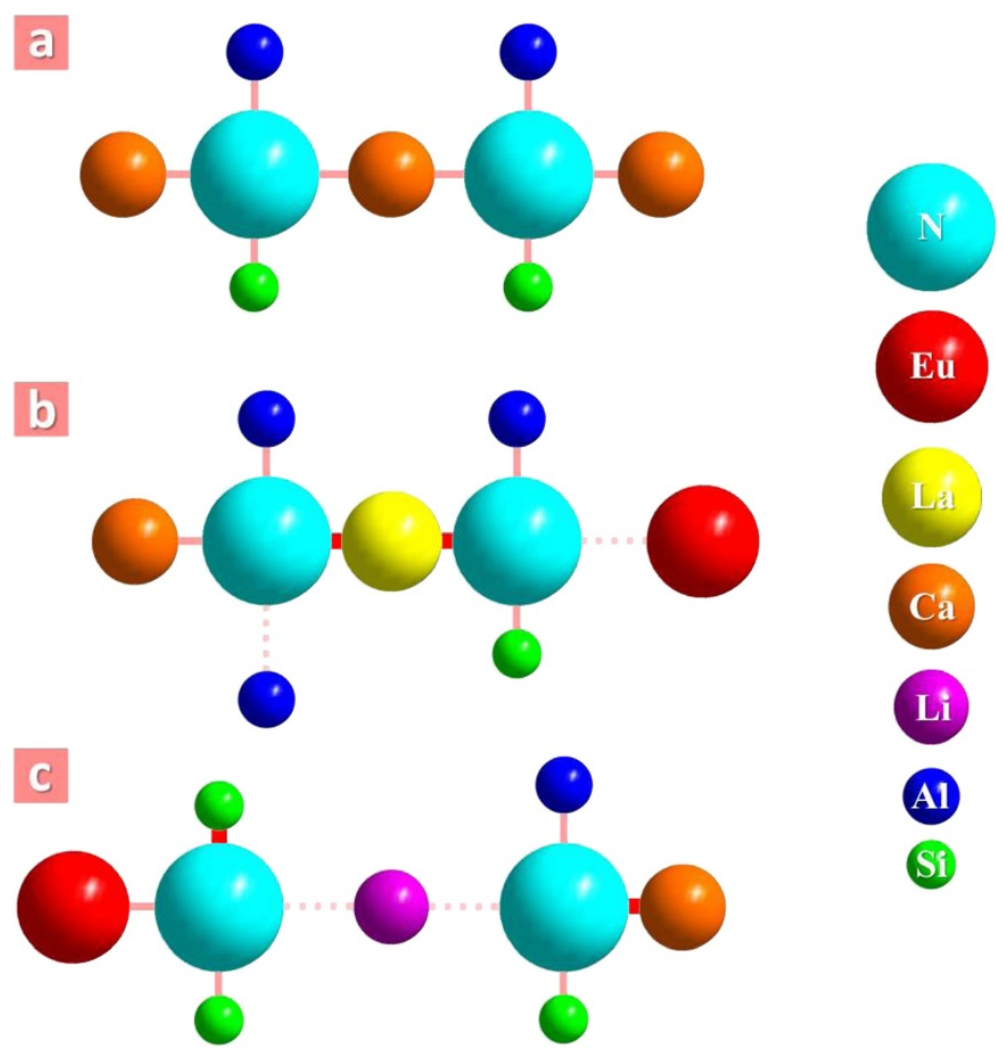

Figure 5 Remotely-controlled mechanisms for (a) $\mathrm{CaAlSiN}_{3}$, (b) $\mathrm{La}$, and (c) Li series lattices. Wide solid lines (deep red) represent the shorter and tauter bonds. Dashed lines (light red) represent the longer and flabbier bonds. (Reprinted with permission from reference [19]. Copyright 2013, American Chemical Society). 


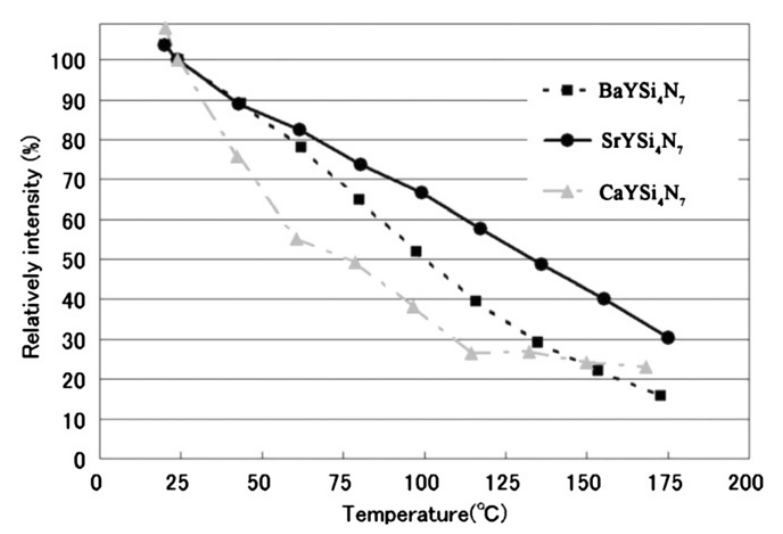

Figure 6 Thermal-dependent relative emission intensity of $\mathrm{Eu}^{2+}$-activated $\mathrm{MYSi}_{4} \mathrm{~N}_{7}(\mathrm{M}=\mathrm{Ca}, \mathrm{Sr}, \mathrm{Ba})$. (Reprinted with permission from reference [20]. Copyright 2010, The Electrochemical Society).

nitride in the $\mathrm{Ba}_{1.95} \mathrm{Eu}_{0.05} \mathrm{Si}_{5-\mathrm{x}} \mathrm{Al}_{\mathrm{x}} \mathrm{N}_{8-\mathrm{x}} \mathrm{O}_{\mathrm{x}}$ system, as shown in Figure $3 \mathrm{~b}$. Therefore, $\mathrm{Ba}^{2+}$ cations are preferentially coordinated by introducing oxide anions. The results imply that the $E_{\mathrm{a}}$ gradually increases with increasing $\mathrm{x}$ value for $\mathrm{M}=\mathrm{Ba}$ (Figure $2 \mathrm{~b}$ ).

Furthermore, a remotely-controlled phenomenon results in a variable photoluminescence of the $\mathrm{CaAlSiN}_{3}$ compound by introducing $\mathrm{Li}^{+} / \mathrm{Si}^{4+}$ and $\mathrm{La}^{3+} / \mathrm{Al}^{3+}$ pairs, as shown in Figure 4. The emission intensities $\left(I_{\mathrm{T}}\right)$ of all components evidently decreased with increasing temperature because of the TQ effect, as illustrated in the right side of Figure 4. The intensities of the samples with $\mathrm{Li}$ inclusion $\left[\left(\mathrm{Ca}_{1-x} \mathrm{Li}_{x}\right)\left(\mathrm{Al}_{1-x} \mathrm{Si}_{1+x}\right) \mathrm{N}_{3}: \mathrm{Eu}\right]$ decreased

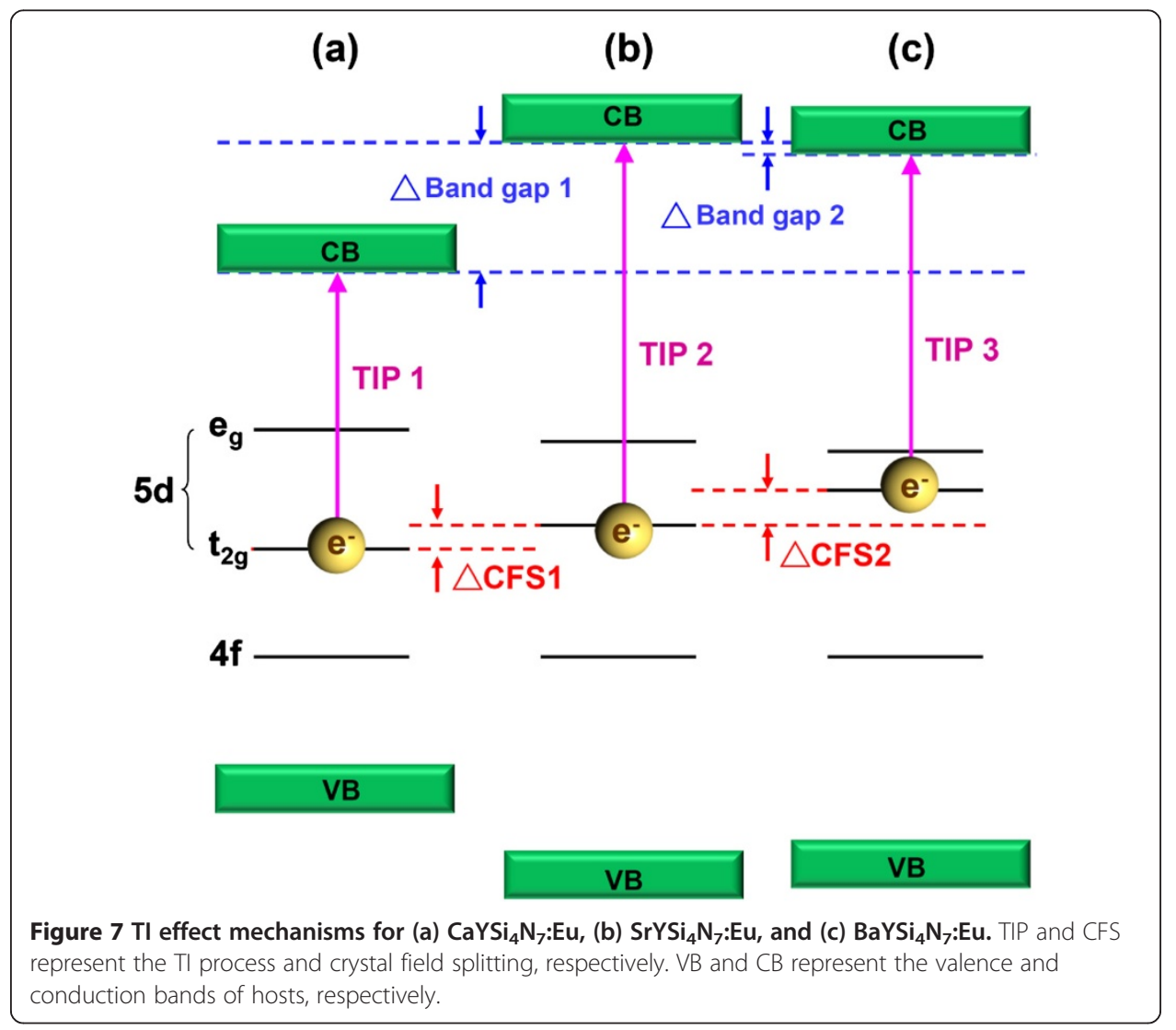



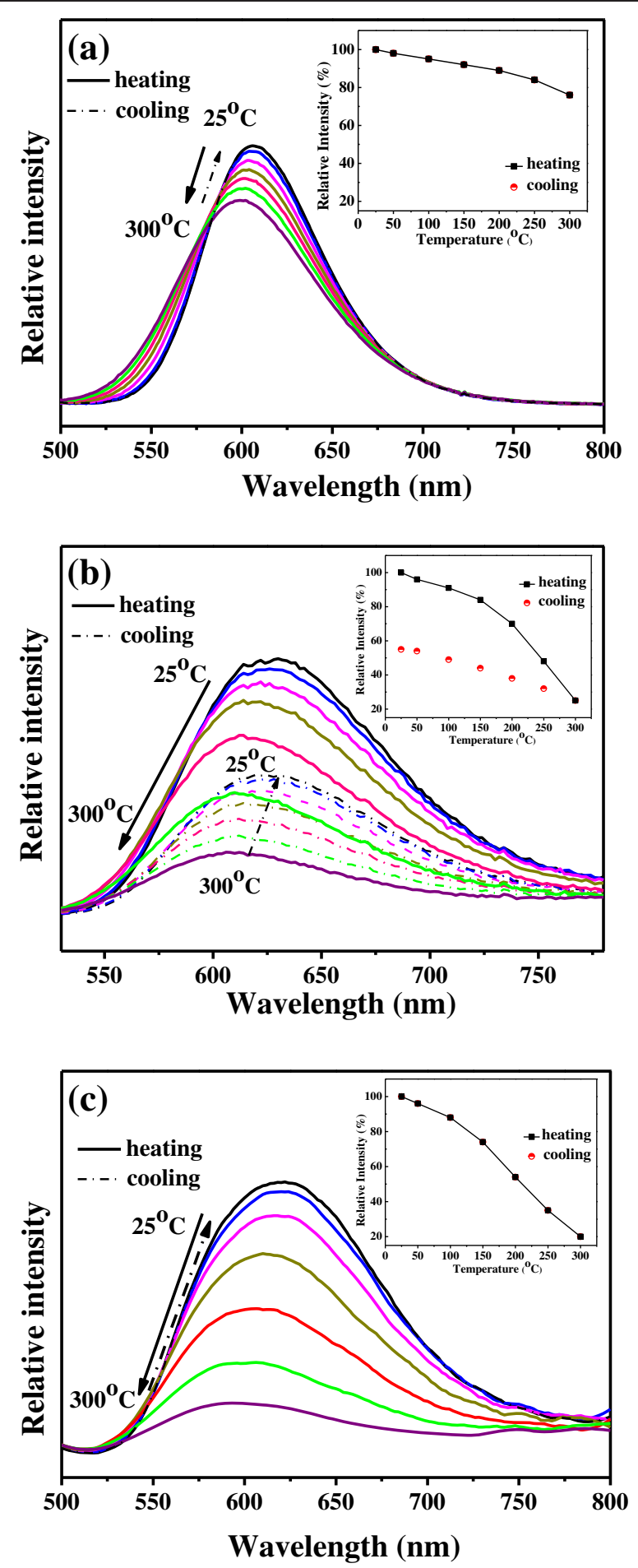

Figure 8 Temperature-dependent luminescent spectra of (a) $\mathrm{Sr}_{2-x} \mathrm{Si}_{5} \mathrm{~N}_{8}: \mathrm{Eu}_{x}(x=0.02)$ (b) $\mathrm{Sr}_{2-x} \mathrm{Si}_{5} \mathrm{~N}_{8}$ : $\mathrm{Eu}_{x}(x=0.10)$, and (c) $\mathrm{Ba}_{2-x} \mathrm{Si}_{5} \mathrm{~N}_{8}: \mathrm{Eu}_{x}(x=0.10)$ heated and reversely cooled as functions of the temperature $\left(25^{\circ} \mathrm{C}\right.$ to $\left.300^{\circ} \mathrm{C}\right)$. Plot of the relative intensity against the temperature is inserted. (Reprinted with permission from reference [16]. Copyright 2012, American Chemical Society). 
slower than that of the $\mathrm{CaAlSiN}_{3}: \mathrm{Eu}^{2+}$ sample $(\mathrm{x}=0)$, but the intensities of the samples with La inclusion $\left[\left(\mathrm{Ca}_{1-x} \mathrm{La}_{x}\right)\left(\mathrm{Al}_{1+x} \mathrm{Si}_{1-x}\right) \mathrm{N}_{3}\right.$ : Eu] decreased rapider than that of the $\mathrm{CaAlSiN}_{3}: \mathrm{Eu}^{2+}$ sample, as displayed in Figure $4 \mathrm{a}$ and b. The TQ $E_{\mathrm{a}}$ gradually improved across all materials from the La-included series ( $\mathrm{x}=0.15$ to 0.03$)$ to the intermediate $\mathrm{x}=0$ sample, and then to the Li-included series ( $x=0.03$ to 0.15$)$, as shown in Figure 4c. These results are inconsistent with the covalence balance, as well as the substitutions of the $\mathrm{LaAl}^{6+}$ and $\mathrm{LiSi}^{5+}$ cation pairs for $\mathrm{CaSi}^{6+}$ and $\mathrm{CaAl}^{5+}$, respectively. The remotelycontrolled mechanisms explain the variations of the quenching behavior observed in Figure 5. The La-N bond is more covalent than the Ca-N bond; however, the Al-N bond is less covalent than the $\mathrm{Si}-\mathrm{N}$ bond with the introduction of the $\mathrm{LaAl}^{6+}$ pair into the $\mathrm{CaAlSiN}_{3}(\mathrm{x}=0)$ sample. Based on the radius, the $\mathrm{Eu}^{2+}$ cation $\left[{ }^{[6]} r\left(\mathrm{Eu}^{2+}\right)=1.17 \AA\right]$ is larger than the $\mathrm{Ca}^{2+}$ cation $\left[{ }^{[6]} r\left(\mathrm{Ca}^{2+}\right)=1.00 \AA\right]$. To minimize the lattice strain, a $\mathrm{Eu}^{2+}$ activator should be preferably contained in the wider $\mathrm{Ca}^{2+}$ site, as shown in the right side of Figure 5b. When the $\mathrm{x}$ value increases, the thermal stability of the La series decreases because of the weak covalent coordination environment for the $\mathrm{Eu}^{2+}$ dopant. However, the rigid bond from the $\mathrm{Eu}^{2+}$ cation improves the thermal stability of the Li series because the $\mathrm{Li}-\mathrm{N}$ bond is less covalent than the $\mathrm{Ca}-\mathrm{N}$ bond and has excess $\mathrm{Si}^{4+}$, as presented in Figure 5c. These particular conditions for the TQ behavior of all $\mathrm{M}_{1.95} \mathrm{Eu}_{0.05} \mathrm{Si}_{5-x} \mathrm{Al}_{x} \mathrm{~N}_{8-\mathrm{x}} \mathrm{O}_{x}, \quad\left(\mathrm{Ca}_{1-x} \mathrm{Li}_{x}\right)\left(\mathrm{Al}_{1-x} \mathrm{Si}_{1+x}\right) \mathrm{N}_{3}: \mathrm{Eu}$, and $\left(\mathrm{Ca}_{1-x} \mathrm{La}_{x}\right)\left(\mathrm{Al}_{1+x} \mathrm{Si}_{1-x}\right) \mathrm{N}_{3}: \mathrm{Eu}$ compounds demonstrated that the local coordination neighborhoods of the $\mathrm{Eu}^{2+}$ activator are susceptible to the nearest anions $\left(\mathrm{N}^{3-}\right.$ and $\left.\mathrm{O}^{2-}\right)$ or cations $\left(\mathrm{La}^{3+}\right.$ and $\left.\mathrm{Li}^{+}\right)$.

\section{TI effect}

The degree of TQ is unpredictable and can be exactly arranged according to the changing ionic radii of the alkali-earth ions in the same system. Similar to $\mathrm{MYSi}_{4} \mathrm{~N}_{7}: \mathrm{Eu}$ $(\mathrm{M}=\mathrm{Ca}, \mathrm{Sr}, \mathrm{Ba})$ compounds, the relative emission intensities of the three samples drastically decreased and are in the order of $\mathrm{Sr}>\mathrm{Ba}>\mathrm{Ca}$ at around $100^{\circ} \mathrm{C}$ (Figure 6). These findings indicate that the excited $5 d$ electrons relax through the anomalous TI,

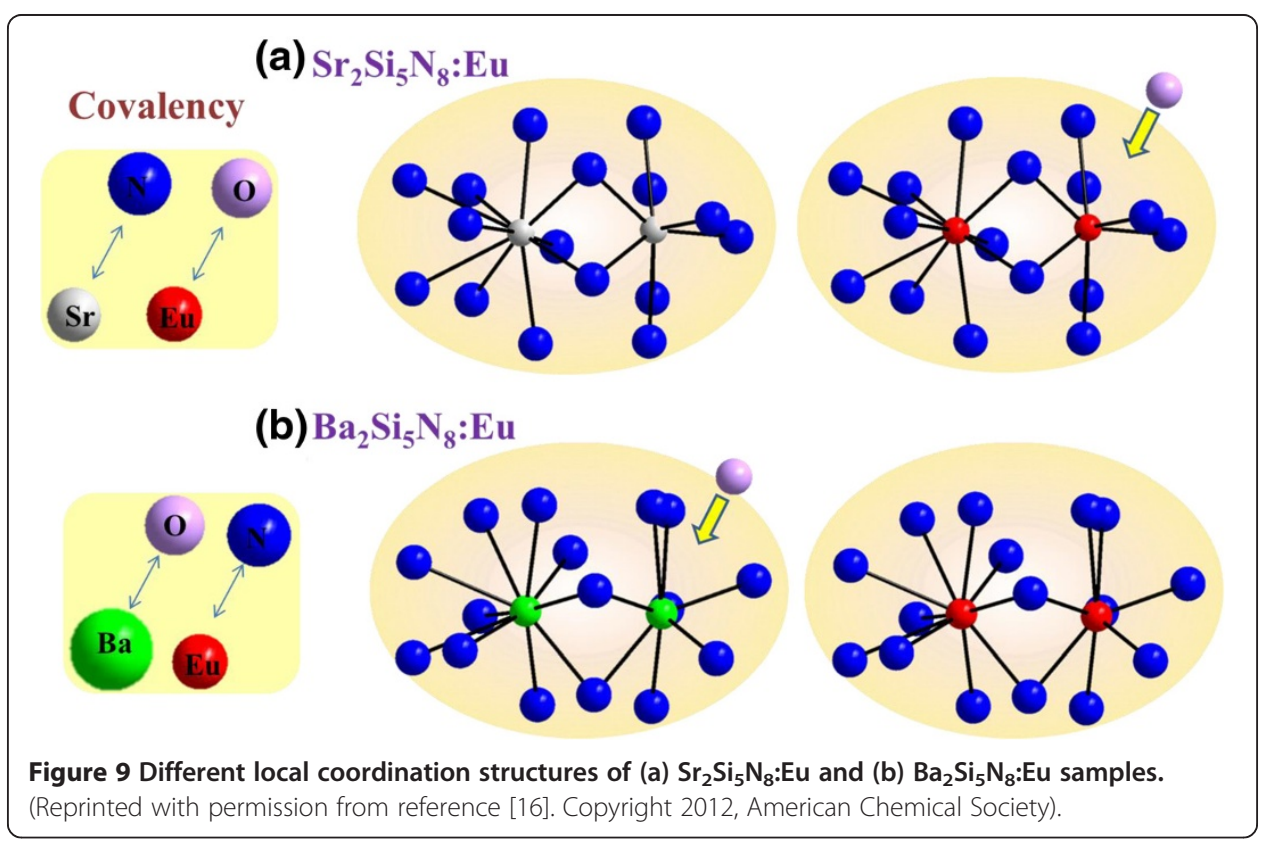


which depends on the distance between the $5 d$ state of the activator and the bottom of the conduction band of the host. The proposed energy level diagram for TI depends on the crystal field splitting of the $5 d$ level of the activators and the computationally determined bandgaps of the hosts, as illustrated in Figure 7. The distinct TI effect and strong TQ occur in the $\mathrm{CaYSi}_{4} \mathrm{~N}_{7}$ : $\mathrm{Eu}$ sample because of its small bandgap of $2.68 \mathrm{eV}$ ( $\Delta$ bandgap $1>>\Delta$ bandgap 2 ). For the $\mathrm{Sr}$ and Ba samples, the deviation in the crystal field splitting for the $\mathrm{Eu}^{2+}(\triangle \mathrm{CFS} 2)$ and the bandgap for the hosts ( $\triangle$ bandgap 2) result in the long TI process (TIP 2) of the $\operatorname{SrYSi}_{4} \mathrm{~N}_{7}$ :Eu compound, which leads to a low TI effect. According to the above-mentioned findings, the bandgap of the hosts and the crystal field splitting of the activators relatively influence the TQ behavior except for the local structure of dopants.

\section{TD effect}

In high-power LED devices, luminescent materials suffer from TD, which is different with TQ and cannot elaborate the thermal behavior at high temperature. The
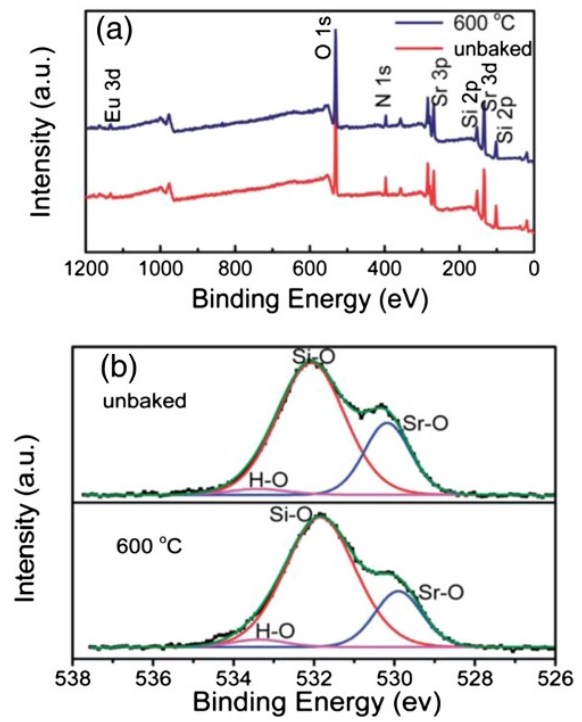
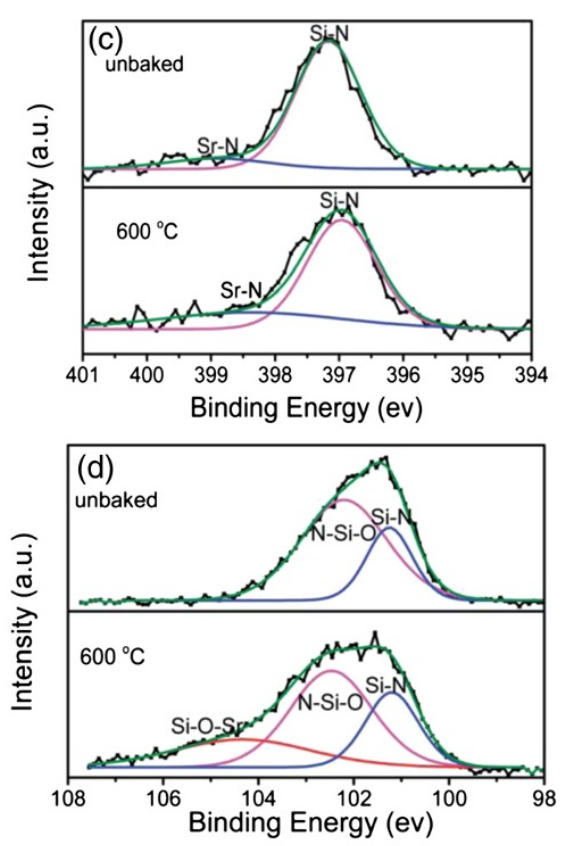

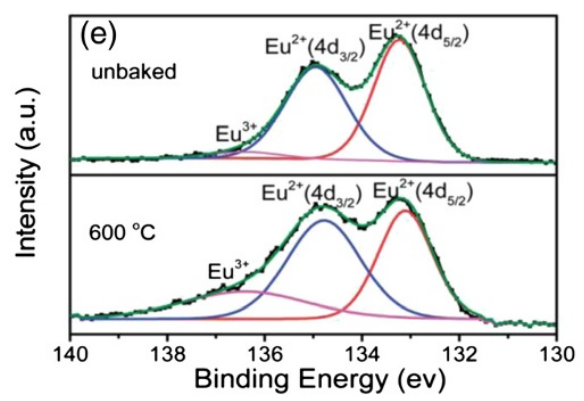

Figure 10 Electron spectroscopy for chemical analysis spectra of (a) $\mathrm{SrSi}_{2} \mathrm{O}_{2} \mathrm{~N}_{2}: \mathrm{Eu}_{0.03}^{2+}$ (baked and unbaked samples) and detailed XPS spectra are shown in (b) $01 \mathrm{~s}$, (c) N $1 \mathrm{~s}$, (d) Si 2p, and (e) Eu 4d, respectively. (Reprinted with permission from reference [17]. Copyright 2014, The Royal Society of Chemistry). 
intensity of $\mathrm{Sr}_{1.98} \mathrm{Si}_{5} \mathrm{~N}_{8}: \mathrm{Eu}_{0.02}$ sample decreases and normally recovers as a function of the surrounding temperature, as shown in Figure 8a. The TD of the $\mathrm{Sr}_{1.9} \mathrm{Si}_{5} \mathrm{~N}_{8}$ : $\mathrm{Eu}_{0.1}$ sample is irreversible (Figure $8 \mathrm{~b}$ ). By contrast, the initial intensity of $\mathrm{Ba}_{1.9} \mathrm{Si}_{5} \mathrm{~N}_{8}: \mathrm{Eu}_{0.1}$ can be recovered from a high temperature to atmospheric conditions (Figure 8c). Based on the literature, alkali earth metals of $\mathrm{M}_{2} \mathrm{Si}_{5} \mathrm{~N}_{8}(\mathrm{M}=\mathrm{Sr}, \mathrm{Ba})$, such as those with 8-coordination and 10-coordination sites, have two kinds of coordinate positions. The alkali earth metals have varying ionic radii $\left[{ }^{[8]} r\left(\mathrm{Ba}^{2+}\right)=1.42 \AA{ }^{[8]} r\left(\mathrm{Sr}^{2+}\right)=\right.$ $1.26 \AA]$, and the europium activator $\left[{ }^{[8]} r\left(\mathrm{Eu}^{2+}\right)=1.25 \AA\right]$ is closed to $\mathrm{Sr}^{2+} \cdot \mathrm{Eu}^{2+}$ is preferentially doped into the 8-coordination site of $\mathrm{Ba}^{2+}$ ion in the $\mathrm{Ba}_{2} \mathrm{Si}_{5} \mathrm{~N}_{8}$ compound because its small radius $\left[{ }^{[8]} r\left(\mathrm{Eu}^{2+}\right)<{ }^{[8]} r\left(\mathrm{Ba}^{2+}\right)\right]$ is suitable for the small space (8-coordination site). However, $\mathrm{Eu}^{2+}$ is randomly doped into the 8-coordination or 10-coordination sites of $\mathrm{Sr}^{2+}$ ion in the $\mathrm{Sr}_{2} \mathrm{Si}_{5} \mathrm{~N}_{8}$ compound because of their similar ionic radii $\left.{ }^{[8]} r\left(\mathrm{Eu}^{2+}\right) \sim{ }^{[8]} r\left(\mathrm{Sr}^{2+}\right)\right]$. Therefore, the covalence of Eu-N in $\mathrm{Ba}_{2} \mathrm{Si}_{5} \mathrm{~N}_{8}$ is higher than that in $\mathrm{Sr}_{2} \mathrm{Si}_{5} \mathrm{~N}_{8}$, which confers thermal stability to $\mathrm{Ba}_{1.9} \mathrm{Si}_{5} \mathrm{~N}_{8}: \mathrm{Eu}_{0.1}$. Upon heating, the mobility of oxygen atoms on the $\mathrm{Sr}_{1.9} \mathrm{Si}_{5} \mathrm{~N}_{8}: \mathrm{Eu}_{0.1}$ surface results in oxidation reaction and forms byproducts. Figure 9 briefly describes the TD mechanism.

In addition, the $\mathrm{SrSiO}_{3}$ formation and the oxidation reaction $\left(\mathrm{Eu}^{2+} \rightarrow \mathrm{Eu}^{3+}\right)$ of $\mathrm{Sr}_{0.97} \mathrm{Si}_{2} \mathrm{O}_{2} \mathrm{~N}_{2}: \mathrm{Eu}_{0.03}^{2+}$ occur during the baking process, as demonstrated in Figure 10. The oxidation reaction is represented by the following chemical equation [22]:

$$
2 \mathrm{Eu}^{2+}+1 / 2 \mathrm{O}_{2}(g)+\mathrm{Vo} \rightarrow 2 \mathrm{Eu}^{3+}+\mathrm{Oo}^{2-}
$$

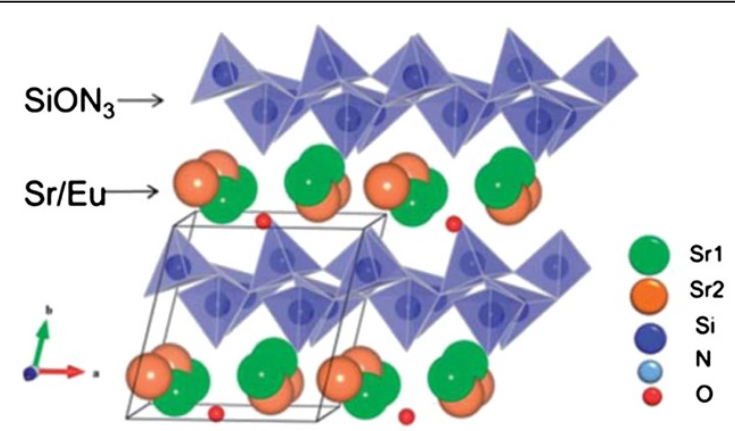

(a)

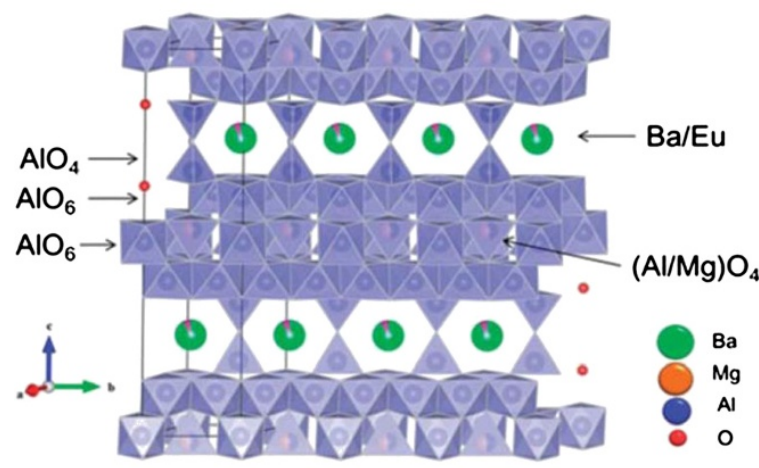

(b)

Figure 11 Crystal structures of (a) $\mathrm{SrSi}_{2} \mathrm{O}_{2} \mathrm{~N}_{2}: \mathrm{Eu}$ and (b) $\mathrm{BaMgAl}_{17} \mathrm{O}_{19}$ :Eu. (Reprinted with permission from reference [17]. Copyright 2014, The Royal Society of Chemistry). 
where $\mathrm{Vo}$ and $\mathrm{Oo}^{2-}$ are the oxygen vacancy and oxygen ion of the lattice, respectively. $\mathrm{Eu}^{2+}$ ions are easily attacked by oxygen because these ions are found between the $\mathrm{SiON}_{3}$ layers and the crystal structure of $\mathrm{BaMgAl}_{17} \mathrm{O}_{19}$, as illustrated in Figure 11 . However, the activators are protected from oxygen by the polyhedron $\operatorname{Eu}(\mathrm{O}, \mathrm{N})_{7}$ in $\alpha$-sialon. As discussed previously, plastic deformation of the luminescent intensity, defined as the irreversible TD, is prevent. By contrast, TQ is a reversible process, and is referred to as the elastic deformation of luminescent intensity.

\section{Conclusions}

In summary, the main effects are generalized and discussed according to the thermal characteristics of various (oxy)nitride phosphors. In addition, thermal concepts that could prevent serious thermal destruction were presented. First, the thermal stability of phosphors is attained through ionic substitution and charge balance, such as $\mathrm{AlO}^{+} \rightarrow$ $\mathrm{SiN}^{+}$and $\mathrm{LiSi}^{5+} \rightarrow \mathrm{CaAl}^{5+}$. Considerable thermal effects depend on the local positions of the activators. Second, the adjustment of the host bandgap can be improved by controlling the host components. Finally, TD can be minimized through surface coating and having excellent crystalline phosphor particles.

Competing interests

The authors declare that they have no competing interests.

Authors' contributions

$\mathrm{CCL}$ analyzed the data and wrote the manuscript. RSL reviewed and scrutinized the entire article. They completed the work together. Both authors read and approved the final manuscript.

Authors' information

Chun Che Lin received his Bachelor degree in Chemistry from Chung Yuan Christian University (Taiwan) in 2005. He obtained his Masters and PhD degrees in Chemistry from National Taiwan University in 2007 and 2011, respectively. He is currently working as a postdoctoral research fellow in the group of Prof. Ru-Shi Liu at the National Taiwan University. His research mainly focuses on the fabrication and lighting applications of rare earth-based functional materials. Ru-Shi Liu is currently a professor at the Department of Chemistry, National Taiwan University. He received his Bachelor's degree in Chemistry from Shoochow University (Taiwan) in 1981. He received his Masters degree in Nuclear Science from the National Tsing Hua University (Taiwan) in 1983. He obtained two PhD degrees in Chemistry: one from National Tsing Hua University in 1990 and one from the University of Cambridge in 1992. He worked at Materials Research Laboratories at the Industrial Technology Research Institute from 1983 to 1985. He was an Associate Professor at the Department of Chemistry of National Taiwan University from 1995 to 1999, and then was promoted to Professor in 1999. His research focuses on the field of Materials Chemistry. He is an author or coauthor of more than 450 publications in international scientific journals. He has also been granted more than 80 patents.

\section{Acknowledgements}

The authors would like to thank the Ministry of Science and Technology of Taiwan (Contract No. MOST 101-2113-M-002014-MY3) for financially supporting this research.

Received: 13 June 2014 Accepted: 8 September 2014

Published online: 24 September 2014

\section{References}

1. Lin CC, Xiao ZR, Guo G-Y, Chan T-S, Liu RS: Versatile phosphate phosphors $\mathrm{ABPO}_{4}$ in white light-emitting diodes: collocated characteristic analysis and theoretical calculations. J Am Chem Soc 2010, 132:3020-3028.

2. Lin CC, Liu RS: Advances in phosphors for light-emitting diodes. J Phys Chem Lett 2011, 2:1268-1277.

3. Im WB, George N, Kurzman J, Brinkley S, Mikhailovsky A, Hu J, Chmelka BF, DenBaars SP, Seshadri R: Efficient and color-tunable oxyfluoride solid solution phosphors for solid-state white lighting. Adv Mater 2011, 23:2300-2305.

4. Park JK, Kim CH, Kim SHP, Park HD: Application of strontium silicate yellow phosphor for white light-emitting diodes. Appl Phys Lett 2004, 84:1647-1649.

5. Smet PF, Parmentier AB, Poelman D: Selecting conversion phosphors for white light-emitting diodes reviews critical reviews in electrochemistry and solid-state science and technology CRES3T. J Electrochem SOc 2011, 158:37-54.

6. DiBartolo B: Optical Interactions in Solids. New York: John Wiley \& Sons; 1968:420-427.

7. Kamimura A, Sugano S, Tanabe Y: Ligand Field Theory and Its Applications. 1st edition. Tokyo: Shokabo; 1969:269-321. 
8. Werts MHV, Jukes RTF, Verhoeven JW: The emission spectrum and the radiative lifetime of $\mathrm{Eu}^{3+}$ in luminescent lanthanide complexes. Phys Chem Chem Phys 2002, 4:1542-1548.

9. Binnemans K: Lanthanide-based luminescent hybrid materials. Chem Rev 2009, 109:4283-4374.

10. Yu JJ, Gong WT, Xiao ZG, Ning GL: Spectral structure of barium-phosphate-silicate phosphor $\mathrm{Ba}_{10}\left(\mathrm{PO}_{4}\right)_{4}\left(\mathrm{SiO}_{4}\right)_{2}: \mathrm{Eu}^{\mathrm{M}+}$. J Lumin 2012, 132:2957-2960.

11. Hirosaki $\mathrm{N}$, Ogata $\mathrm{S}$, Kocer $\mathrm{C}$ : Ab initio calculation of the crystal structure of the lanthanide $\mathrm{Ln}_{2} \mathrm{O}_{3}$ sesquioxides. J Alloys Comp 2003, 351:31-34.

12. van der Kolk E, de Haas JTM, Bos AJJ, van Eijk CWE, Dorenbos P: Luminescence quenching by photoionization and electron transport in a $\mathrm{LaAlO}_{3}: \mathrm{Ce}^{3+}$ crystal. J Appl Phys 2007, 101:083703.

13. Dorenbos P: Energy of the first $4 f^{7}-4 f^{6} 5 d$ transition of $\mathrm{Eu}^{2+}$ in inorganic compounds. J Lumin 2003, 104:239-260.

14. Lyu L-J, Hamilton DS: Radiative and nonradiative relaxation measurements in $\mathrm{Ce}^{3+}$ doped crystals. J Lumin 1991, 48\&49:251-254.

15. Dorenbos P: Thermal quenching of $\mathrm{Eu}^{2+} 5 d-4 f$ luminescence in inorganic compounds. J Phys Condens Matter $2005,17: 8103-8111$.

16. Yeh C-W, Chen W-T, Liu R-S, Hu S-F, Sheu H-S, Chen J-M, Hintzen HT: Origin of thermal degradation of $\mathrm{Sr}_{2-x} \mathrm{Si}_{5} \mathrm{~N}_{8}: \mathrm{Eu}_{x}$ phosphors in air for light-emitting diodes. J Am Chem Soc 2012, 134:14108-14117.

17. Wang C-Y, Xie R-J, Li FZ, Xu X: Thermal degradation of the green-emitting $\mathrm{SrSi}_{2} \mathrm{O}_{2} \mathrm{~N}_{2}: \mathrm{Eu}^{2+}$ phosphor for solid state lighting. J Mater Chem C 2014, 2:2735-2742.

18. Chen W-T, Sheu H-S, Liu RS, Attfield JP: Cation-size-mismatch tuning of photoluminescence in oxynitride phosphors. J Am Chem Soc 2012, 134:8022-8025.

19. Wang S-S, Chen W-T, Li Y, Wang J, Sheu H-S, Liu RS: Neighboring-cation substitution tuning of photoluminescence by remote-controlled activator in phosphor lattice. J Am Chem Soc 2013, 135:12504-12507.

20. Kurushima T, Gundiah G, Shimomura Y, Mikami M, Kijima N, Cheetham AK: Synthesis of Eu ${ }^{2+}$-activated $\mathrm{MYSi}_{4} \mathrm{~N}_{7}$ $(\mathrm{M}=\mathrm{Ca}, \mathrm{Sr}, \mathrm{Ba})$ and $\mathrm{SrYSi}_{4-x} \mathrm{Al}_{x} \mathrm{~N}_{7-x} \mathrm{O}_{x}(x=0-1)$ green phosphors by carbothermal reduction and nitridation. $J$ Electrochem Soc 2010, 157:J64-J68.

21. Bhushan S, Chukichev MV: Temperature-dependent studies of cathodoluminescence of green band of $\mathrm{ZnO}$ crystals. J Mater Sci Lett 1988, 7:319-321

22. Bizarri $\mathrm{G}$, Moine $\mathrm{B}: \mathrm{On} \mathrm{BaMgAl}{ }_{10} \mathrm{O}_{17}: \mathrm{Eu}^{2+}$ phosphor degradation mechanism: thermal treatment effects. J Lumin 2005, 113:199-213.

doi:10.1186/s40539-014-0016-3

Cite this article as: Lin and Liu: Thermal effects in (oxy)nitride phosphors. Journal of Solid State Lighting 2014 1:16.

Submit your manuscript to a SpringerOpen ${ }^{\circ}$ journal and benefit from:

- Convenient online submission

- Rigorous peer review

- Immediate publication on acceptance

- Open access: articles freely available online

- High visibility within the field

- Retaining the copyright to your article

Submit your next manuscript at $\gg$ springeropen.com 